\title{
Operationalizing the Benefit of Information Radiators from an Awareness Point of View
}

\author{
Stefan Lippert ${ }^{1} \mathbb{D} \cdot$ Michael Koch $^{1}$
}

Received: 23 June 2021 / Accepted: 6 October 2021 / Published online: 23 October 2021

(c) The Author(s) 2021

\begin{abstract}
In this paper, we present a grounded theory research for the benefit information radiators provided using the concept of awareness. Information radiators are ubiquitous installations that disseminate information that is likely to improve awareness in semi-public environments. We discuss potential awareness benefits of information radiators and how these can be provided. Furthermore, we examine how to address several awareness facets that correlate with the benefits to contribute to this goal. The results aim to close the research gap about the benefit of information radiators considered from an awareness point of view.
\end{abstract}

Keywords Ambient display $\cdot$ Awareness $\cdot$ Awareness radiator $\cdot$ Benefit $\cdot$ Information radiator $\cdot$ Large screen $\cdot$ Pervasive display $\cdot$ Public screen

\section{Introduction}

Already in 2001, Alistair Cockburn coined the term "information radiator" to describe a class of displays placed at high-visibility locations that continuously display contextually relevant information to passers-by [22]. Information radiators show content beyond classical workplaces in semipublic environments [71]. They visualize information that is usually hidden in databases, and increase informedness by displaying the information to the semi-public [78]. In their various forms they are ubiquitous [3] - it is hard to imagine our daily work and private life without them [54]. Through information radiators it is possible to get content that was not actively requested, but which nevertheless increases the level of informedness of the recipient $[15,90]$. Since they help to increase awareness of different conditions and activities, information radiators can be seen as awareness tools.

The basic concept of awareness can be explained as knowledge of the activities and status of the people with whom one works in teams, communities or networks [68]. Dourish and Bellotti describe awareness as "an understanding of the activities of others, which provides a context for

Stefan Lippert

Stefan.Lippert@unibw.de

1 Universität der Bundeswehr München, Werner-Heisenberg-Weg 39, 85577 Neubiberg, Germany your own activity" [33]. Awareness is a core component for successful and efficient social interaction [48] and aims at promoting that an individual recognizes what is happening in his specific and topic-related context [35]. As shown in Fig. 1, awareness is about creating a connectivity between humans and technologies and in a further step it is also connecting the interacting people [7]. Information and awareness are transmitted through direct interaction as well as through peripheral perception.

Regarding information radiators as socio-technical systems, the three different dimensions design, reception, and benefits must be differentiated.

- The design of information radiators does not focus on some core components-different forms and manifestations depending on the specific context are possible.

- Information radiators can be used in various ways and it is possible to speak of the more general term of reception instead of use.

- The benefit of information radiators is what they contribute as added value to the usage context. It is currently argued quite superficially only-e.g., in the context of improved informedness.

A first and important step is to conceptualize the benefit of information radiators to map it to characteristic categories in a context-specific manner. We pursue the idea of looking at 


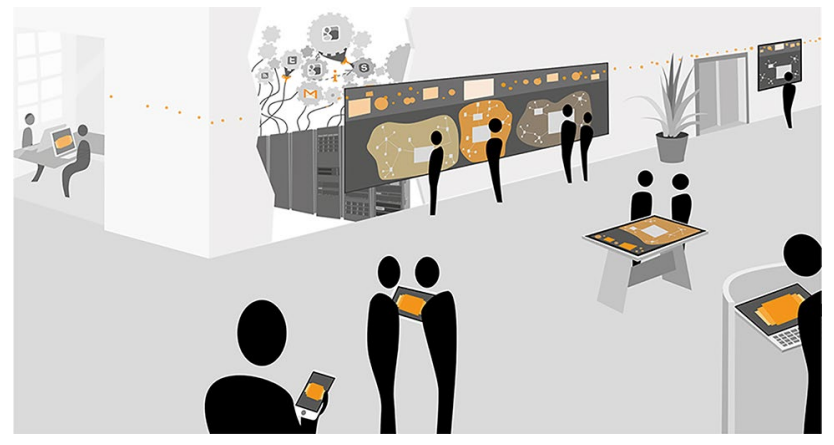

Fig. 1 Illustration of the variety of information radiators and interacting entities [89]

benefit from the perspective of awareness, which is why it is necessary to identify and, if necessary, establish correlations between these two dimensions. Awareness is a cross-sectional aspect of information radiators, as it influences all three sociotechnical layers and has an impact on the entire system. The influence and effects of awareness on design and reception of information radiators have already been sufficiently discussed and scientifically evaluated in the literature [51, 93, 95].

We are going to provide a clear understanding about how the benefit of information radiators can be operationalized. For this purpose, different solution approaches, which together form a whole, were identified and precisely defined. The identification of characteristic benefit categories in the area of sociotechnical systems, the specification of awareness facets as abstraction variants, and consequently the establishment of correlations between these two scopes. Thus, the best possible goal-oriented design of an information radiator can be achieved, and the justification of the benefit is possible. Both result as consequence of the establishment of correlations between the facets and the benefit categories.

Therefore, in the following, we first investigate the theoretical foundations: benefit of information radiators, impacts and effects of improved awareness and approach to benefit via awareness facets (Chapter 2). Afterwards, we present our research method (Chapter 3) and showcase the results of this paper: awareness facets, correlations between facets and benefits and first lessons for design (Chapter 4). We finish this paper with the discussion of the results: study results, limitations, future work, and implications (Chapter 5).

\section{Theory}

\section{Benefit of Information Radiators}

As a sociotechnical system, an information radiator can generate benefit in a variety of ways. In this context, the benefit of information radiators is generally not doubted [93]. However, the discussion usually stays superficial, and there is disagreement about how, where and when a practical benefit exists [86]. Awareness can be described in the context of the present work as a way of considering benefits. However, it must be mentioned that the presentation of the benefit can never be complete because of the enormous range of applications [80, 86, 93]. The benefit of information systems can be summarized by identifying knowledge gaps and to close them [102]. The immaterial benefits are becoming an important focus of research.

The benefit of information radiators can only be assessed by understanding their design and reception. Because design is what makes reception possible in the first place, and without actual reception, no benefit can be generated. In other words, one could say that without the design there can be no reception, and without the reception there can be no use. On the one hand, there are reciprocal relationships between these three dimensions, and on the other hand, they are mutually dependent. In the case of information radiators, the question of what their benefit is and how it can be determined fails to come to the fore. Therefore, the idea and approach of this paper is to investigate the benefit of information radiators from the awareness point of view. There is a large consensus between science and practice that it is good to improve awareness $[80,86,93]$. There are also various studies and other scientific publications that deal with prototypes for the specific improvement of awareness in a particular context $[60,77,105]$.

From the existing work $[60,77,80,86,93,105]$, the following categories were selected as core components of the benefit of information radiators. This cannot be fully achieved because of the immense variety and continuous addition of new applications that need to be considered. The following benefit categories of information radiators were selected. They provide the best possibility to operationalize the benefits of information radiators:

- Improvement of cohesion of members within an organizational group and of external members in relation to a specific group $[85,87,100]$.

- Improvement of satisfaction of single members within an organizational group from an individual perspective and with the group as a whole [12, 30, 97].

- Improvements in identification of members with their organizational group, a greater sense of belonging and thus a stronger bond between them [26, 53, 83].

- Improvement of attractiveness of single members within an organizational group from an individual perspective and with the group as a whole $[9,58,120]$.

- Improvement of motivation of the single members, also connected with a greater willingness to take on new tasks 
as well as to carry out and complete existing projects [1, $52,80]$.

- Improvement of productivity of the organizational group, mostly manifested in faster and optimized individual and organizational task and goal fulfillment [29, 36, 117].

- Improvement of collaboration within an organizational group, manifested in a greater willingness to share information and knowledge and not to hold back $[6,56,96]$.

- Improvement of time saving in individual and organizational task fulfilment, regularly realized through faster completion of projects and general time saving [31, 63, 111].

This list can by no means be called exhaustive. Nevertheless, it is representative enough to be mentioned here, to allow further considerations and to make the context clearer. The benefit of information radiators is only comprehensible from an understanding of the design and reception and requires this prerequisite to be properly classified and understood in its specific context. The mentioned benefit categories can characteristically be regarded as providing benefits.

\section{Impacts and Effects of Improved Awareness}

Even if the benefit may seem subtle, awareness has a crucial impact on organizational groups [50]. Especially gentle factors such as effectiveness, the quality of decisions or the harmony within a team are influenced by the degree of informedness [23]. Making implicit knowledge explicitly available and enabling members to share their knowledge with each other is becoming more and more important for corporate management [103]. Despite many new forms of communication and interaction, that are already ubiquitously available, networking is often difficult due to spatial and temporal limitations [99].

Each information that helps to better specify the situation of a person or a place is important for interactions and improves the current awareness [28]. The major problem of organizational groups supported by technology is the availability of knowledge and awareness information that should be instantly available to everyone [112]. Awareness information is usually exchanged subtly [43]. If a personal meeting is not possible, this information must be conveyed through information radiators, because they help single persons within their groups to fulfil their tasks [49].

The audience of information radiators can be classified according to [46] into four different categories: active users, passive users, viewers, and passers-by. These categories use the behavior as benchmark and must be taken into account across possible application scenarios [46]. Passive users in particular, i.e. those who do not actively use the system but nevertheless participate, for example by observing an active user of an information radiator, are increasingly in the focus of application development because they have turned from a side issue to a target group that must be taken seriously into account [17].

\section{Approach to Benefit Via Awareness Facets}

This paper aims to close the research gap about the benefit of information radiators considered from an awareness point of view. Furthermore, we examine how to address several awareness facets that correlate with the benefits to contribute to this goal. To answer this research question, we complement the heterogeneous consideration of benefits with the dimension of the role of awareness. For this purpose, the awareness facets from a specific socio-technical perspective were identified. They represent the abstraction of what the conveyance of awareness means, and which types exist regarding design and functionality. As linking possibilities, they are characteristic for the assessment of the different benefit categories of information radiators from the perspective of awareness.

For this purpose, the awareness facets were identified from a specific socio-technical perspective with a focus on information radiators and could be located within their relation to the other components in the socio-technical model (Fig. 2). The design forms the foundation for the use of an information radiator and is intended to depict and prepare for a specific deployment scenario. The use should lead to the reception of the presented information particles, which is not only due to active or passive users but can also extend towards merely spectators and seemingly passive passers-by. Reception may result in benefits such as increased reach, better understanding of previously hidden information, or approaching the most ideal level of information possible.

Awareness is a cross-cutting issue for information radiators, since it influences design, reception, and benefits, as well as having an impact on the entire socio-technical system. Awareness facets can only be properly understood if the

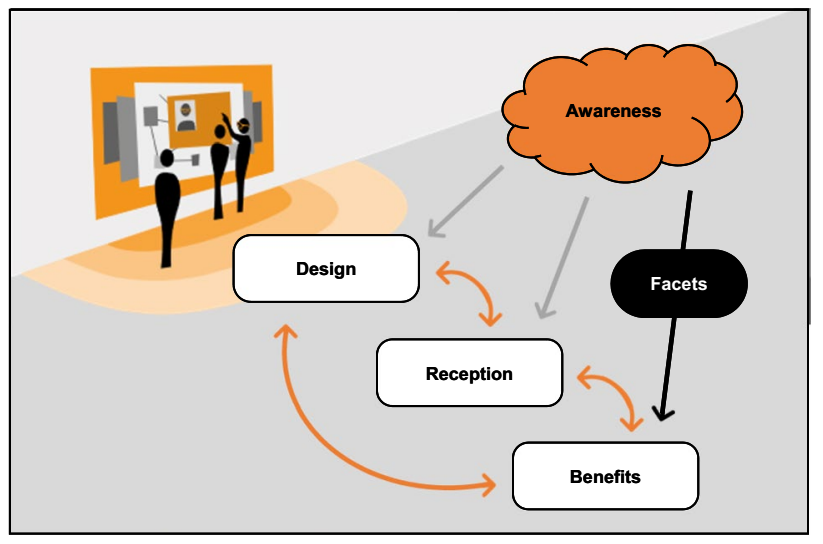

Fig. 2 Awareness facets within a socio-technical model 
socio-technical layers are considered, since both the design and the reception and especially the benefits do not exist independently and autonomously, because they are embedded in relational interdependencies.

\section{Methodology}

We identify the awareness facets that answer as abstraction variants different questions: what does awareness mean, which variants do exist considering design and functionality, and what's their correlations to the different benefit categories.

The research method is based on the grounded theory [118]. This method is useful when few thematically relevant studies have been conducted so far or when there is a need to evolve a new theory. It is a dynamic and cyclical process that iteratively diverges between the existing evidence pool and the theory to be developed. In this process, the three necessary paradigms induction, abduction and deduction are alternately and reciprocally applied. As a result, the evolving theory will be more and more condensed until it is both, plausible and comprehensible. On this foundation, the awareness facets could be identified and initially operationalized in order to make them applicable and manageable for the further course of the research.

The grounded theory allows data collection, data analysis and theory building to be carried out in one process and the respective results to be used in the other categories as well. The research question is basically open-ended so that it can be successively advanced through various iterations over the empirical data and recorded and modified in more detail, which is a prerequisite for the proper application of grounded theory. The core of the chosen methodology is the evaluation of the empirical data material through a multistage procedure that iteratively, parallel, and reflexively conducts the analysis as well as coding. There are three distinct and distinguishable types of results to which this research method can contribute: theory building, model building, and comprehensive description [118].

The systematic literature research for the identification, compilation, and extraction of the awareness facets was conducted in April 2019. The databases ACM Guide to Computing Literature [2], IEEE Xplore Digital Library [59] and Springer Link [108] as well as Google Scholar [47] were used as basis. For the development of the search strategy, various preliminary queries were conducted to create the final search term:

("awareness-" OR "of awareness") AND (facet* OR dimension* OR aspect* OR value* OR type* OR ratio* OR class $^{*}$ OR group $*$ OR categor* OR kind* OR form $*$ ) AND "information system"
The period from January 1990 to April 2019 was selected as temporal filter to sort out results that are outdated and don't reflect the latest state of art. In accordance with the snowball principle, further relevant and interesting papers could be chosen from the selected articles. The search was not limited to specific fields such as title or abstract, rather included the entire contributions, i.e. the title as well as the abstract, the complete text and assigned keywords.

In the present study, the approach of Kitchenham [67] was favored and adopted in the core phases. This approach is illustrated in Fig. 3 using the PRISMA flow diagram. The 'screening' step was modified because the detection and elimination of duplicate contributions normally follows immediately after the 'identification' phase. This procedure was not practicable due to the number of papers, so a check for duplicates was only carried out after the abstracts had been examined and were removed at this stage of the systematic literature search.

The analysis and classification of existing information radiators should lead to correlations between the awareness facets and the different benefit categories. Since many of the design and functional recommendations taken from theory and practice have already been incorporated into the development of new information radiators, the selection of 33 systems classified in the present study is limited to those whose scientific findings have been published since 2014. A brief and clear presentation summary of the results in the form of mentioned benefit categories and awareness facets can be found in the appendix. By analyzing and classifying these up-to-date prototypical information radiators, correlations between the awareness facets and the benefit categories could be specified. Criteria for the selection were not only relevance, but also the greatest possible representativeness and the coverage of different application scenarios, interaction possibilities, objectives, research methodologies and results. This is intended to provide a comprehensive and characteristic analysis of information radiators from practice and to create the greatest possible coverage for the empirical study.

The classification, i.e. the assignment of awareness facets and benefit categories to prototypical information radiators, was done by manual tagging. This causes both positive and negative implications. On the positive side, the awareness facets were established as a result of the present work and thus have not yet been commonly adopted. An assignment of these facets to existing information radiators had to be made therefore in particular also by an own understanding of the systems, their functions and functionalities. Negative effects such as the lack of verification of the performed tagging by other scientists could be minimized by extending the investigation and tagging to existing secondary literature. 
Fig. 3 PRISMA-flow chart of the systematic literature search

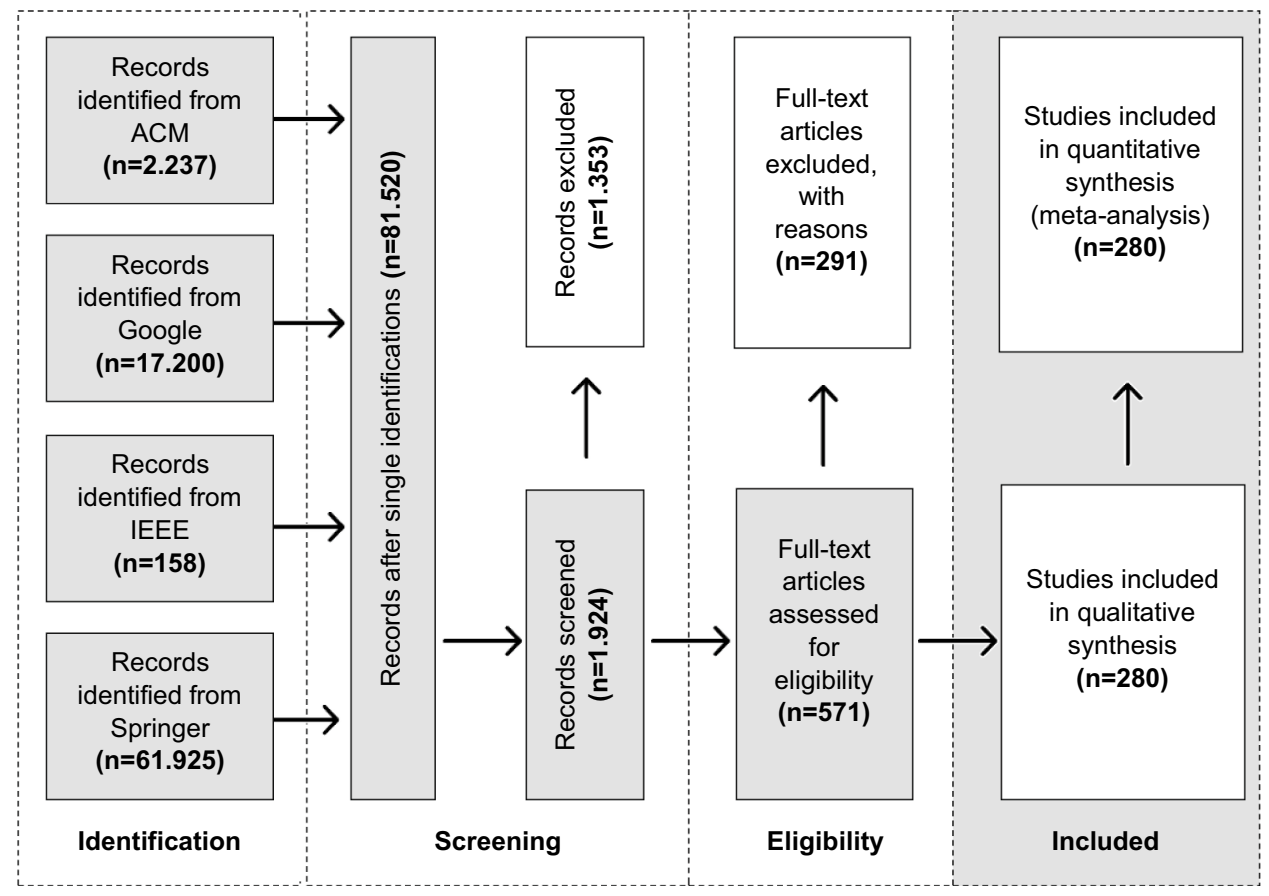

\section{Results}

\section{Awareness Facets}

The awareness facets that could be derived and evaluated as a result of the literature study, will be described in the following. They represent the abstraction of what the conveyance of awareness means, and which types exist regarding design and functionality. They provide a comprehensive representation of what distinguishes awareness in information radiators and how these abstractions can be described and made usable.
Figure 4 shows the awareness facets from a specific sociotechnical perspective with a focus on information radiators. This representation attempts to illustrate the localization of the facets within the socio-technical environment as precisely as possible. The following list of awareness facets can be probably expanded and should not be considered as all-inclusive and final.

Understandability of information through contextbased classification possibilities of information particles. A displayed information is not only to be considered independently and therefore has a stand-alone validity demand. Every specific information can be understood

Fig. 4 Awareness facets in the context of information radiators

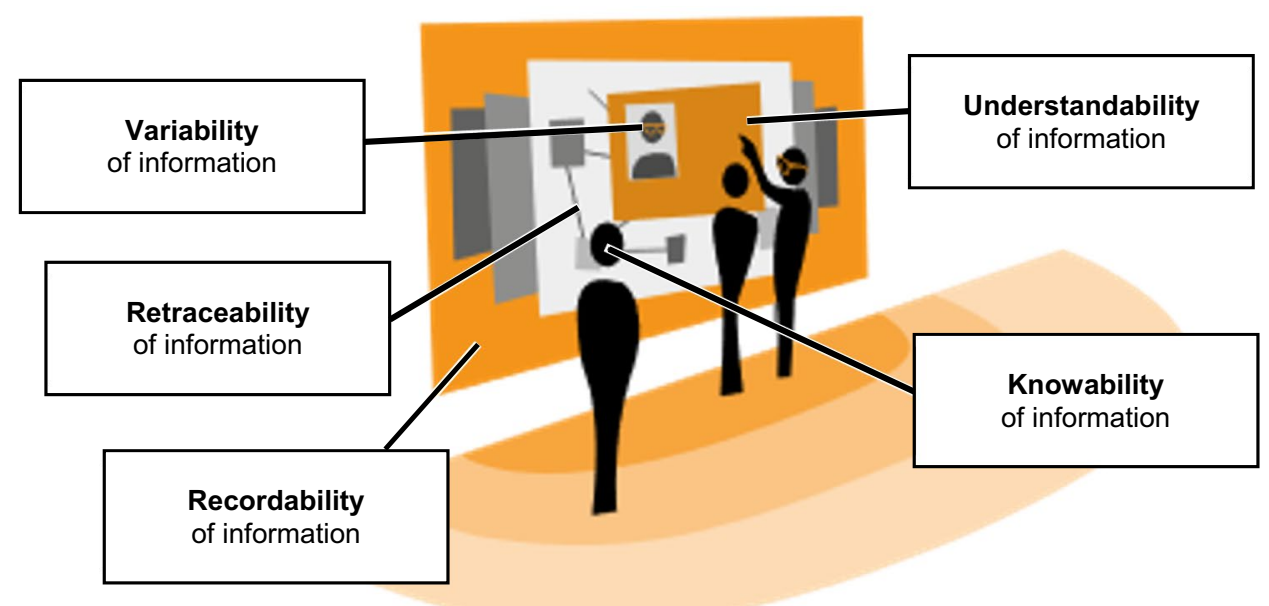


additionally in its context. A user can see what the exact meaning of an information particle and how it can be subjectively and individually classified in a particular context [8, 12, 13, 27, 58, 73, 74, 88, 100, 105].

Retraceability of information through visibility of all connections between information particles. Not only encapsulated information objects are isolated represented, but also their connections to other information particles can be visualized and received. This results in a grid of different information, which, depending on the system and the framework used, is person-centric or otherwise grouped and whose connections are visualized per se or after a user interaction. Thus it should become comprehensible where an information has its origins, from which authority it emerges and how it is embedded in the higherlevel information structure $[12,37,41,45,56,61,74,84$, 100, 107].

Recordability of information through proactive and interaction-independent visualization of information particles. Through the request-free representation of single information objects and their links, a surprisingly but still purposefully aligned information proposal for users is visualized. Information are displayed that would otherwise have remained hidden and thus could not be received and used. This is also mirrored in an increase in the range of information. In an ideal case, the displayed information particles are of current or virtual relevance to the user. The overall presentation and displaying of linked information particles make information accessible and usable to a wider audience, that were rarely or never been requested before $[29,36,44,56,81,82,98,101$, 106, 116].

Variability of information through variation possibilities of the displayed level of detail of information particles. Users of an information radiator have an increased knowledge of the particularity. In addition, the graduality of a displayed information particle can be influenced and multi-dimensionally manipulated by user interactions or independently through the backend. The scaling can be enabled while displaying the single information objects and the additionally showed linked objects can be adjusted vertically in depth as well as horizontally in width [10, 29, 31, 41, 58, 61, 75, 84, 94, 101].

Knowability of information through improved informedness about information particles in the respective context. It is possible to achieve an increase in the level of informedness, which is defined as being able to improve the performance of tasks by individuals or within groups. The intention is to enable an ideal level of information, e.g. by displaying information objects, visualizing their links and other actions that occur in the context of information radiators $[18,19,31,38,56,61,75,76,92,104]$.

\section{Correlations between Facets and Benefits}

The results are, up to now, not sufficient to enable the intended usability of the awareness facets regarding the benefits of information radiators from the perspective of awareness. To address this question, correlations between the awareness facets and the different benefit categories of information radiators were established. A proper correlation between different socio-technical layers for information radiators is not fully created in the paper. For the specific listing of the correlations by using manual tagging, it can be stated: first, the core publication of the respective prototype was read and analyzed so that an initial impression of its intended functional scope and mode of operation could be gained. In addition, initial notes were made about possible awareness facets and benefit categories. In an iterative process, these initial findings were either discarded or plausibilized by consulting extant secondary literature that addressed the targeted information radiator. Subsequently, those elements that were most accurate and confidently mapped were adopted as the final attribution and classification.

The correlations are suitable for existing systems as well as for the development and design of new information radiators: the awareness facets lead to different benefit categories which can subsequently be used for the benefit argumentation. Also, the benefit categories are linked to the facets and imply specific general and abstract design recommendations.

The correlations between the awareness facets and the different benefits of information radiators in Fig. 5 allow a taxation of the benefits. As results from the analysis of 33 prototypical information radiators, the correlations can be assigned an acceptance, even if their verification remains future work. The awareness facets represent the abstraction of what the conveyance of awareness means, and which types exist regarding design and functionality.

In summary, the relationships between the awareness facets and their respective benefits have been excerpted from different studies and applied in the context on which this paper is based. Nevertheless, it must be noted that this is still interpretative information whose concrete characteristics and effects should be further investigated in practical applications. As noted, the benefits of information radiators cover a wide range and are both tangible and not intangible.

\section{First Lessons for Design}

Having derived awareness facets and correlations to benefit categories, one can continue to think about lessons for 
Fig. 5 Correlations between awareness facets and benefit categories

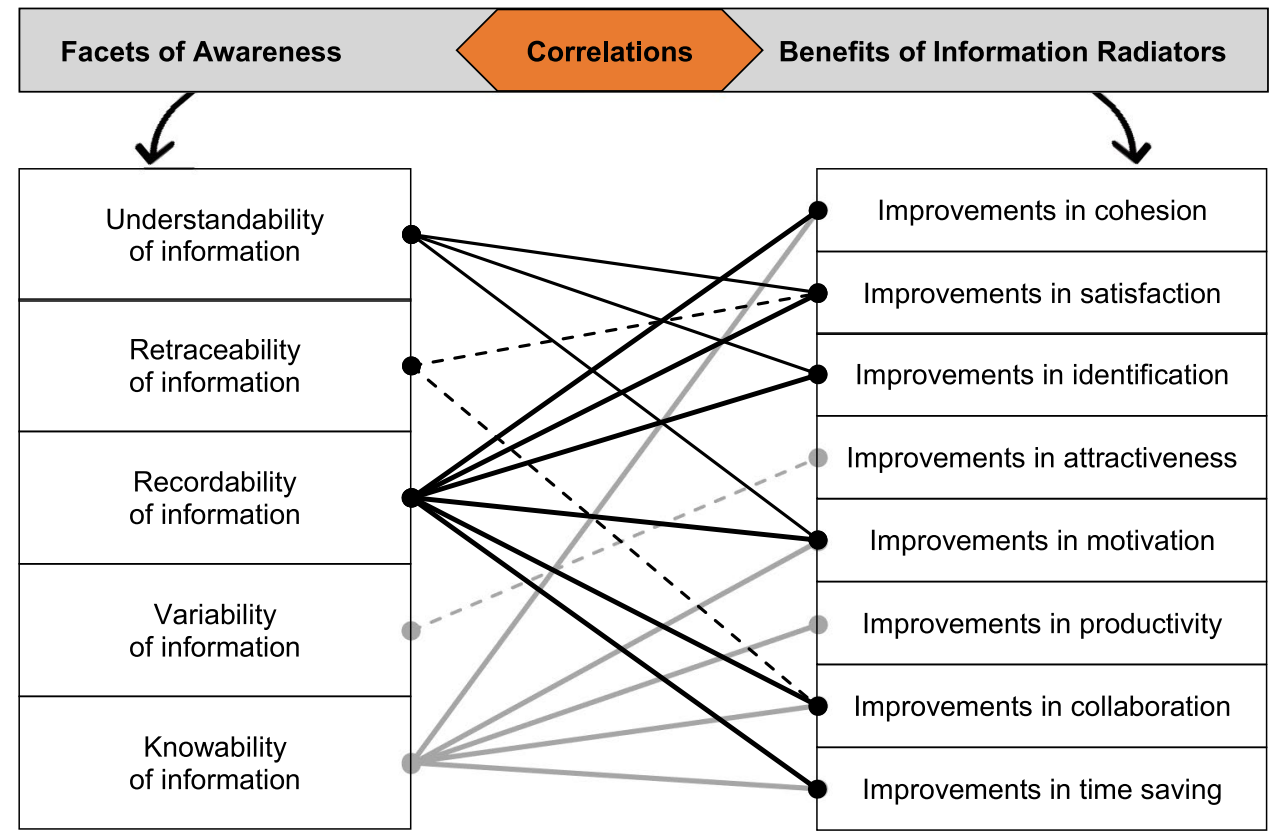

design. A brief overview of the design recommendations for the different facets of awareness will be addressed in the following. As a result, the facets become more tangible and it is obvious how they could be realized, at least initially. Since these design-recommendations are general and abstract, they can only provide initial indications and do not represent a detailed design manual. Nevertheless, the considerations improve the practical value of the facets.

- Understandability of information: enable individual evaluation and classification by displaying the context and environment variables.

- Retraceability of information: display and clearly illustrate connections between the objects and positioning within the information structure.

- Recordability of information: additional visualization of objects through proactive and interaction-independent representations.

- Variability of information: influence of the displayed particularity and scaling of the current level of detail by the user.

- Knowability of information: visualization of objects with current or virtual content relevance for the potential user of the system.

The design of information radiators is not concentrated on a few essential components but can take different forms and manifestations depending on their specific context of use. Therefore, to understand the benefits of information radiators, it is important to consider that the design has a significant impact on the reception. Only a successful implementation and user-oriented design will lead to potential users becoming active or passive recipients. Without reception, in contrast, no benefit can be generated, so the aim is to achieve the greatest possible reception, which can have a clearly positive effect on the benefit of information radiators.

The results of the present study can help in the design and planning of a new project by following the design recommendations presented above. Two dimensions must be distinguished: the conscious implementation of awareness facets via the design recommendations aims at making the correlating benefit categories retrievable, so that a project is able to implement particular benefits. It is also possible to estimate and rate the benefits that a planned system will be able to realize.

\section{Discussion}

\section{Study Results}

The compilation of the different expressions of the sociotechnical layers design, reception and benefit cannot be described as complete at all. Nevertheless, they are representative enough to enable further considerations and to make the context clearer. An insight into design, reception and benefit could be offered. In addition to the benefits of information radiators, the awareness facets and the correlations between these two dimensions were made more plausible and explained in their causal and relational contexts. 
A comprehensive representation of what characterizes awareness among information radiators and how these abstractions can be described and derived in the form of concrete facets and thus made usable could be realized. These aspects should be taken into consideration from developers of a specific information radiator and from operators, to provide a benefit argumentation and to develop and design a system that is most effectively oriented towards particular benefits.

Clearly, the correlations shown in Fig. 5 do not consider some of the links between categories of benefits of information radiators and awareness facets. A correlation that could not be obtained by classifying the 33 prototypical system applications was not determined and considered. Also, there are some correlations that could have been made on the base of the classification, but which were discarded because the actual existence of a connection was judged to be insufficient due to inadequate empirical evidence.

The problem of quantifying the results of the present study can be broken down into different dimensions. Stumpp highlights the difficulty of quantification because an objective calculation of the relevant values seems to be impossible [109]. The quantification and generalization of the awareness facets and their correlations is just limited possible. Also, the results were obtained by using a clearly defined and limited context. This context should be considered for plausibility in the quantification and generalization.

\section{Limitations}

It should be critically noted that in the present study neither prototypes were developed, nor applications were implemented, nor independent empirical studies were conducted. A further limiting factor for the validity of the awareness facets and their correlations with different benefits of information radiators can be found on the level of cultural and linguistic transferability. It should also be critically noted that the awareness facets and their correlations with specific benefit categories of information radiators were identified by manual tagging.

The graphical drawing of the correlations shown in Fig. 5 should also be regarded as a limitation. This mode has been adopted to provide a clear view of the interrelationships. Furthermore, there are additional possibilities and variations in methodology. Even more precise would be the usage of Venn diagrams and/or heatmaps, maybe even a combination of both.

\section{Future Work}

The preparation of design recommendations, which are formulated in significantly more detail in guidelines and are capable of mapping different contexts, is to be considered as future work. In practice, the use of the facets in the development and design of applications must be evaluated, regarding enabling certain benefits via awareness facets. The transfer from information radiators in particular to information systems in general should also be investigated.

\section{Implications}

The correlations between the awareness facets and the benefit categories of information radiators can help designing and planning of new projects by applying the suggested design recommendations. It is possible to estimate the benefits that a planned system can realize by assigning the different awareness facets.

As the results of the classification have shown, the awareness facets lead to correlations with different benefit categories. The general solution of mapping each of the facets cannot be implemented and would cause negative implications: for example, the applications would become very extensive, the development would require more resources and the complexity could lead to an overload of systems. Finally, it would be conceivable that all of these factors could lower acceptance, and lead to a possible non-use. Therefore, it is advisable to focus on those facets that are most likely to be able to reproduce particular benefits. The correlations between the awareness facets and the possible benefit categories of information radiators are suitable both for existing systems and for the development and design of new information radiators.

The established design recommendations can serve as an overview of the results and upcoming challenges that must be achieved to create more knowledge about the context of the components within information radiators. The design has a clear influence on the reception and benefit of information radiators, because without a user-oriented presentation and passing on of information, the use and reception suffers, so that the intended generation of benefits will only be possible to a very limited extent, if at all. It was shown which awareness facets can trigger specific benefits of information radiators. However, since they are not features or gadgets in the classical sense, they can only give an initial indication of how a possible implementation within a particular system might look like. 


\section{Conclusion}

Information radiators display information-sensitive content in a context-specific manner and thus enable benefit that can only be obtained by considering its design and reception. Awareness has been used as a cross-sectional topic that influences the socio-technical layers of design, reception and benefit of an information system, as well as the correlation between these dimensions. Understandability, retraceability, recordability, variability and knowability of information as awareness facets represent the abstraction of what the conveyance of awareness means, and which types exist regarding design and functionality.

The correlations between the awareness facets and the benefit categories of information radiators are the result of the present study and show what the benefit of using information radiators consists of and how it can be determined and specified with the consideration of the role of awareness as influencing factor. The correlations enable the benefit argumentation for information radiators and the implementation of design recommendations. Both dimensions are suitable for existing and still planned information radiators: the awareness facets lead to different benefit categories, which can subsequently be used for the benefit argumentation, on the other hand the benefit categories are in each case linked to the facets, from which specific general-abstract design recommendations can be derived. Thus, the best possible goal-oriented design of a system can be implemented and the justification of the benefit - both as a consequence of establishing the correlations between the facets and the benefit categories.

All in all, the correlations between the awareness facets and the benefit categories provide a reasoning aid to show that an existing or planned information radiator is capable of triggering positive impacts in a specific area. It can be clarified both that a specific benefit can be achieved and how this is best addressed from a design perspective.

\section{Appendices}

\section{Abbreviations of the Facets and Benefit Categories}

A.1.1 Awareness facets.
A: Understandability of information.
B: Retraceability of information.
C: Recordability of information.

D: Variability of information.

E: Knowability of information.

\section{Benefit Categories}

1: Improvements in cohesion.

2: Improvements in satisfaction.

3: Improvements in identification.

4: Improvements in attractiveness.

5: Improvements in motivation.

6: Improvements in productivity.

7: Improvements in collaboration.

8: Improvements in time saving.

\section{Short Version Classification of Information Radiators}

AutoCardSorter [64]—A, 6, 8 .

aWall [84]—B, E, 1, 6, 7, 8.

Bazaar [57]—A, 4, 5.

BodyLenses [66]—A, C, 2, 5.

CCW [55]—B, D, 2, 7.

CPR Display [91]-C, E, 1, 3.

DISCOVER [20]-A, E, 2, 5.

Don't Disturb Me [5]-E, 6, 8.

Eye Fishing [65] $-\mathrm{C}, 1$.

Fair Numbers [72]—C, E, 1, 4.

Fishification [78]-D, 4.

GazeHorizon [121]—C, 5 .

GlobalFestival [119]—D, 4, 5.

GravitySpot [4]-A, 2.

Groupgarden [110]-B, C, E, 5, 7.

IdeaMirror [70]-C, D, E, 2, 5.

Information Wall [79]-C, E, 5, 8.

LUME [16]—A, 3.

Media Ribbon [113]—C, 7.

MeetingMirror [69]-A, B, C, D, E, 2, 3, 4.

Mercury [21]-A, E, 6, 8.

MStoryG [62]-C, 8.

MyPosition [114]-C, 3 .

OrMiS [14]-B, D, E, 6, 7.

Proxemic Flow [115]-B, 2.

Public DisPLAY [24]-C, 2, 7.

Puppeteer Display [11]-C, 1, 2.

Selfie Cafe [39]—C, 3, 5.

ShadowTouch [34]-A, E, 1, 3.

SpiderEyes [32]-B, 1, 7 .

StreetSmart [25]—B, 2. 
UbiOpticon [42]-A, C, 2.

WishBoard [40]-A, 1, 3.

Funding Open Access funding enabled and organized by Projekt DEAL.

\section{Declarations}

Conflict of interest There are no relevant financial or non-financial competing interests to this study.

Ethical approval This article does not contain any studies with human participants or animals performed by any of the authors.

Open Access This article is licensed under a Creative Commons Attribution 4.0 International License, which permits use, sharing, adaptation, distribution and reproduction in any medium or format, as long as you give appropriate credit to the original author(s) and the source, provide a link to the Creative Commons licence, and indicate if changes were made. The images or other third party material in this article are included in the article's Creative Commons licence, unless indicated otherwise in a credit line to the material. If material is not included in the article's Creative Commons licence and your intended use is not permitted by statutory regulation or exceeds the permitted use, you will need to obtain permission directly from the copyright holder. To view a copy of this licence, visit http://creativecommons.org/licenses/by/4.0/.

\section{References}

1. Aboelmaged MG. Knowledge sharing through enterprise social network (ESN) systems: motivational drivers and their impact on employees' productivity. J Knowl Manag. 2018;22:362-83. https://doi.org/10.1108/JKM-05-2017-0188.

2. Association for Computing Machinery. 2021. Browse digital library. https://dl.acm.org/browse/

3. Alpar P, Alt R, Bensberg F, Weimann P. Anwendungsorientierte wirtschaftsinformatik. In: Strategische planung, entwicklung und nutzung von informationssystemen. 9th ed. Wiesbaden: Springer; 2019.

4. Alt F, Bulling A, Gravanis G, Buschek D. GravitySpot: guiding users in front of public displays using on-screen visual cues. In: Proceedings of the 28th Annual ACM symposium on user interface software and technology (UIST '15). Charlotte; 2015. pp 47-56

5. Alt F, Torma S, Buschek D. Don't disturb me-understanding secondary tasks on public displays. In: Proceedings of the international symposium on pervasive displays (PerDis'16). Oulu; 2016. pp 1-12

6. Andriole SJ. Business impact of web 2.0 technologies. Commun ACM. 2010;53:67-79. https://doi.org/10.1145/1859204.

7. Antunes P, Sapateiro C, Pino JA, et al. Awareness checklist: reviewing the quality of awareness support in collaborative applications. In: Proceedings of the 16th international conference on collaboration and technology (CRIWG '10). Maastricht; 2010. pp 202-217

8. App S. Virtuelle teams. Freiburg: Haufe-Lexware; 2013.

9. Aral S, Dellarocas C, Godes D. Introduction to the special issue. Social media and business transformation: a framework for research. Inf Syst Res. 2013;24:3-13. https://doi.org/10. 1287/isre.1120.0470.

10. Beitel M, Ferrer E, Cecero JJ. Psychological mindedness and awareness of self and others. J Clin Psychol. 2005;61:739-50. https://doi.org/10.1002/jclp.20095.

11. Beyer G, Binder V, Jäger N, Butz A. The puppeteer display: attracting and actively shaping the audience with an interactive public banner display. In: Proceedings of the international conference on designing interactive systems (DIS '14). Vancouver; 2014. pp 935-944

12. Bhattacherjee A, Lin C-P. A unified model of IT continuance: three complementary perspectives and crossover effects. Eur J Inf Syst. 2014;24:1-10. https://doi.org/10.1057/ejis.2013.36.

13. Bhattacherjee A, Premkumar G. Understanding changes in belief and attitude toward information technology usage: a theoretical model and longitudinal test. MIS Q. 2004;28:229-54.

14. Bortolaso C, Oskamp M, Phillips G, et al. The effect of view techniques on collaboration and awareness in tabletop mapbased tasks. In: Proceedings of the 2014 ACM international conference on interactive tabletops and surfaces (ITS '14). Dresden; 2014. pp 79-88

15. De BO, Spence R. Serendipity within a ubiquitous computing environment: a case for opportunistic browsing. In: Ubicomp 2001 ubiquitous computing, LNCS 2201. Berlin: Springer; 2001. p. 362-9.

16. Casalegno F, Lim Y, Winfield $\mathrm{C}$ et al. LUME-building identity, displaying content, and engaging users through network of interactive display. In: Proceedings of the international symposium on pervasive displays (PerDis '14). Copenhagen; 2014. pp 192-193

17. Chamberlain A, Bødker M, Hazzard A, et al. Audio technology and mobile human computer interaction. Int J Mob Hum Comput Interact. 2017;9:25-40. https://doi.org/10.4018/IJMHCI. 2017100103.

18. Chen C, Zhao G, Yu Y, Deng H. Multiple views system to support awareness for cooperative design. Comput Des. 2015;63:3951. https://doi.org/10.1016/j.cad.2015.01.001.

19. Chen EC, Mallinckrodt B. Attachment, group attraction and self-other agreement in interpersonal circumplex problems and perceptions of group members. Group Dyn Theory Res Pract. 2002;6:311-24. https://doi.org/10.1037//1089-2699.6.4.311.

20. Cheung V. Increasing passersby engagement with public large interactive surfaces. Dissertation, University of Waterloo. 2016

21. Clinch S, Mikusz M, Greis M, et al. Mercury: an application store for open display networks. In: Proceedings of the international joint conference on pervasive and ubiquitous computing (UbiComp'14). Seattle; 2014. pp 511-522

22. Cockburn A. Communicating, cooperating teams. In: Agile software development. Boston: Addison-Wesley; 2001. p. 75-111.

23. Cooper RB, Haines R. The influence of workspace awareness on group intellective decision effectiveness. Eur J Inf Syst. 2008;17:631-48. https://doi.org/10.1057/ejis.2008.51.

24. Cox T, Carter M, Velloso E. Public DisPLAY: social games on interactive public screens. In: Proceedings of the Australian conference on computer-human interaction (OzCHI '16). Launceston; 2016. pp 371-380

25. Cremonesi P, Di Rienzo A, Frà C, et al. Personalized interaction on large displays: the StreetSmart project approach. In: Proceedings of the 2014 international working conference on advanced visual interfaces (AVI '14). Como; 2014. pp 353-354

26. Dabbish L, Kraut RE. Controlling interruptions: awareness displays and social motivation for coordination. In: Proceedings of the 2004 ACM conference on computer supported cooperative work (CSCW '04). Chicago; 2004. pp 182-191 
27. Daly AJ, Moolenaar NM, Bolivar JM, Burke P. Relationships in reform: the role of teachers' social networks. J Educ Adm. 2010;48:359-91. https://doi.org/10.1108/09578231011041062.

28. Dey AK, Abowd GD. Towards a better understanding of context and context-awareness. In: Proceedings of the 1st international symposium on handheld and ubiquitous computing (HUC '99). Karlsruhe; 1999. pp 304-307

29. Dhuieb MA, Laroche F, Bernard A. Context-awareness: a key enabler for ubiquitous access to manufacturing knowledge. Proced CIRP. 2016;41:484-9. https://doi.org/10.1016/j.procir.2015. 12.027 .

30. DiMicco JM, Geyer W, Millen DR, et al. People sensemaking and relationship building on an enterprise social network site. In: Proceedings of the 42nd Hawaii international conference on system sciences (HICSS '09). Maui; 2009. pp 1-10

31. Dorwal P, Sachdev R, Gautam D, et al. Role of whatsapp messenger in the laboratory management system: a boon to communication. J Med Syst. 2016;40:1-5. https://doi.org/10.1007/ s10916-015-0384-2.

32. Dostal J, Hinrichs U, Kristensson PO, Quigley A. SpiderEyes: designing attention- and proximity-aware collaborative interfaces for wall-sized displays. In: Proceedings of the international conference on intelligent user interfaces (IUI '14). Haifa; 2014. pp $143-152$

33. Dourish P, Bellotti V. Awareness and coordination in shared workspaces. In: Proceedings of the 1992 ACM conference on computer-supported cooperative work (CSCW '92). Toronto; 1992. pp 107-114

34. Elhart I, Scacchi F, Niforatos E, Langheinrich M. ShadowTouch: a multi-user application selection interface for interactive public displays. In: Proceedings of the 4th international symposium on pervasive displays (PerDis '15). Saarbrücken; 2015. pp 209-215

35. Endsley MR. Toward a theory of situation awareness in dynamic systems. Hum Factors. 1995;37:32-64.

36. Evans NJ, Jarvis PA. The group attitude scale: a measure of attraction to group. Small Group Behav. 1986;17:203-16.

37. Farooq U. Supporting creativity: Investigating the role of awareness in distributed collaboration. Dissertation, The Pennsylvania State University. 2008

38. Farooq U, Ganoe CH, Carroll JM, Lee Giles C. Supporting distributed scientific collaboration: implications for designing the CiteSeer collaboratory. In: Proceedings of the 40th annual hawaii international conference on system sciences (HICSS '07). Big Island; 2007. pp 1-10

39. Ferreira V, Anacleto J, Bueno A. Designing ICT for thirdplaceness. In: Nijholt A, editor. Playable cities, gaming media and social effects. Singapore: Springer; 2017. p. 211-33.

40. Ferreira V, Anacleto J, Bueno A. WishBoard: promoting selfexpression in public displays to leverage the notion of community. In: Proceedings of the workshop on doing CSCW research in Latin America-differences, opportunities, challenges, and lessons learned @ CSCW’15. Vancouver; 2015.pp 1-4

41. Flepp C, Meier G, Burkhard R, et al. Du siehst mich, wenn ich dich auch sehe-reziproke awareness als gestaltungskriterium für orte virtuell-informeller kommunikation wie z.B. ein virtuelles Café. In: Gesellschaft für Arbeitswissenschaft EV, editor., et al., GfA-Frühjahrskongress. Arbeit in komplexen Systemen. Digital, vernetzt, human?! (Bd. 28, § A.2.1). Dortmund: GfA-Press; 2016. p. 1-6.

42. Foth M, Heikkinen T, Ylipulli J, et al. UbiOpticon: participatory sousveillance with urban screens and mobile phone cameras. In: Proceedings of the international symposium on pervasive displays (PerDis '14). Copenhagen; 2014. pp 56-61

43. Fox A, Johanson B, Hanrahan P, Winograd T. Integrating information appliances into an interactive workspace. IEEE Comput Graph Appl. 2000;20:54-65.
44. Frey BS. Geld oder anerkennung? Zur ökonomik der auszeichnungen. Perspekt der Wirtsch. 2010;11:1-15.

45. Gaver WW. Situating action II: affordances for interaction: the social is material for design. Ecol Psychol. 1996;8:111-29. https://doi.org/10.1207/s15326969eco0802_2.

46. Gentile V, Khamis M, Sorce S, Alt F. They are looking at me! Understanding how audience presence impacts on public display users. In: Proceedings of the 6th ACM international symposium on pervasive displays (PerDis '17). Lugano; 2017. pp 1-7

47. Google. Google scholar. 2021. https://scholar.google.com

48. Gross T, Koch M. Computer-supported cooperative work. München: Oldenbourg Wissenschaftsverlag; 2007.

49. Gross T, Stary C, Totter A. User-centered awareness in computer-supported cooperative work-systems: structured embedding of findings from social sciences. Int J Hum Comput Interact. 2005;18:323-60. https://doi.org/10.1207/s15327590ijhc1803_5.

50. Gutwin C, Greenberg S. Workspace awareness for groupware. In: Proceedings of the conference on human factors in computing systems (CHI '96). Vancouver; 1996. pp 208-209

51. Gutwin C, Roseman M, Greenberg S. A usability study of awareness widgets in a shared workspace groupware system. In: Proceedings of the 1996 ACM conference on computer supported cooperative work (CSCW '96). Boston; 1996. pp 258-267

52. Haines R, Kramer M, Vehring N. Activity awareness as a means to promote connectedness, willingness to do additional work, and congeniality: an experimental study. In: Proceedings of 32nd international conference on information systems (ICIS '11). Shanghai; 2011. pp 4:1-4:14

53. Henry KB, Arrow H, Carini B. A tripartite model of group identification: theory and measurement. Small Group Res. 1999;30:558-81.

54. Herczeg M, Koch M. Allgegenwärtige mensch-computer-interaktion. Inform Spektrum. 2015;38:290-5. https://doi.org/10.1007/ s00287-015-0901-1.

55. Heslop P, Preston A, Kharrufa A, et al. Evaluating digital tabletop collaborative writing in the classroom. INTERACT 2015 Part II. 2015;9299:531-48. https://doi.org/10.1007/978-3-319-22723-8.

56. Hornecker E, Marshall P, Dalton NS, Rogers Y. Collaboration and interference: awareness with mice or touch input. In: Proceedings of the 2008 ACM conference on computer supported cooperative work (CSCW '08). San Diego; 2008. pp 167-176

57. Hosio S, Goncalves J, Lehdonvirta V, et al. Situated crowdsourcing using a market model. In: Proceedings of the 27th annual ACM symposium on user interface software and technology (UIST '14). Honolulu; 2014. pp 55-64

58. Huijnen CAGJ, Jsselsteijn WA, Markopoulos P, de Ruyter B. Social presence and group attraction: exploring the effects of awareness systems in the home. Cogn Technol Work. 2004;6:414. https://doi.org/10.1007/s10111-003-0141-z.

59. Institute of Electrical and Electronics Engineers. Xplore: advancing technology for humanity. 2021. https://ieeexplore.ieee.org/ Xplore/home.jsp

60. Janson A, Ernst S, Lehmann K, Leimeister JM. Creating awareness and reflection in a large-scale IS lecture: the application of a peer assessment in a flipped classroom scenario. In: Proceedings of the 4th workshop on awareness and reflection in technologyenhanced learning (ARTEL '14). Graz; 2014. pp 35-50

61. Jeners NU. Unterstützung von Wissensarbeit durch Integration heterogener Kooperationswerkzeuge. Dissertation, RWTH Aachen University. 2015

62. Jorge C, Nisi V, Hanna J, et al. MStoryG: exploring serendipitous storytelling within high anxiety public spaces. INTERACT 2015 Part IV. 2015;9299:335-53.

63. Kaiser H. Zur definition von selektivität, spezifität und empfindlichkeit von analysenverfahren. Fresenius Z für Anal Chem. 1972;260:252-60. 
64. Katsanos C, Tselios N, Goncalves J, et al. Multipurpose public displays: can automated grouping of applications and services enhance user experience? Int J Hum Comput Interact. 2014;30:237-49. https://doi.org/10.1080/10447318.2013. 849547.

65. Khamis M, Alt F, Bulling A. A field study on spontaneous gaze-based interaction with a public display using pursuits. In: Adjunct proceedings of the 2015 ACM international joint conference on pervasive and ubiquitous computing and the $2015 \mathrm{ACM}$ international symposium on wearable computers (UbiComp '15/ ISWC '15). Osaka; 2015. pp 863-872

66. Kister U, Reipschläger P, Matulic F, Dachselt R. BodyLensesembodied magic lenses and personal territories for wall displays. In: Proceedings of the international conference on interactive tabletops and surfaces (ITS '15). Funchal; 2015. pp 117-126

67. Kitchenham B. Procedures for performing systematic reviews. Altenstadt: Eversleigh; 2004.

68. Koch M. Awareness. In: Enzyklopädie der wirtschaftsinformatik. Online-Lexikon. 2009. https://www.enzyklopaedie-der-wirts chaftsinformatik.de/wi-enzyklopaedie/lexikon/daten-wissen/ Informationsmanagement/IT-Infrastruktur/Informations--undKommunikationstechnologien/computer-supported-cooperativework-cscw/awareness. Accessed 2 Feb 2020

69. Koch M, Lösch E, Nutsi A, Ott F. MeetingMirror-unterstützung von wissenschaftler-communities auf konferenzen. In: Proceedings der konferenz gemeinschaften in neuen medien (GeNeMe '15). Dresden; 2015. pp 1-10

70. Koch M, Möslein KM. Idea mirrors-Unterstützung von innovation in unternehmen durch community-awareness. In: Procedings der konferenz gemeinschaften in neuen medien (GeNeMe '06). Dresden; 2006. pp 259-270

71. Koch M, Ott F. CommunityMirrors als informationsstrahler in unternehmen: von abstraktem kontext zu realen arbeitsumgebungen. Inform Spektrum. 2011;34:153-64. https://doi.org/10. 1007/s00287-010-0517-4.

72. Koeman L, Kalnikaitè V, Rogers Y, Bird J. What chalk and tape can tell us: lessons learnt for next generation urban displays. In: Proceedings of the international symposium on pervasive displays (PerDis '14). Copenhagen; 2014. pp 130-135

73. Koppel M, Walter R. Chained displays: configurations of public displays can be used to influence actor-, audience-, and passerby behavior. In: Proceedings of the SIGCHI conference on human factors in computing systems (CHI '12). Austin; 2012. pp 317-326

74. Krogstie BR, Schmidt AP, Kunzmann C, et al. Linking reflective learning and knowledge maturing in organizations. In: Proceedings of the 3rd workshop on awareness and reflection in technology enhanced learning. Paphos; 2013. pp 13-28

75. Kusunoki D, Sarcevic A, Zhang Z, Yala M. Sketching awareness: a participatory study to elicit designs for supporting ad hoc Emergency Medical Teamwork. Comput Support Coop Work. 2015;24:1-38. https://doi.org/10.1016/bs.mcb.2015.01.016. Observing.

76. Lea M, Spears R, De Groot D. Knowing me, knowing you: anonymity effects on social identity processes within groups. Pers Soc Psychol Bull. 2001;27:526-37. https://doi.org/10.1177/ 0146167201275002.

77. Lischke L, Mayer S, Wolf K, et al. Screen arrangements and interaction areas for large display work places. In: Proceedings of the 5th ACM international symposium on pervasive displays (PerDis '16). Oulu; 2016. pp 228-234

78. Maier S, Burkhard M, Lachenmaier P, et al. Fishification-visualizing activity streams using the aquarium metaphor. In: Proceedings of the GeNeMe '13. Dresden; 2013. pp 73-82
79. Mäkelä V, Heimonen T, Luhtala M, Turunen M. Information wall: evaluation of a gesture-controlled public display. In: Proceedings of the 13th international conference on mobile and ubiquitous multimedia (MUM '14). Melbourne; 2014. pp 228-231

80. Mäntymäki M, Riemer K. Enterprise social networking: a knowledge management perspective. Int J Inf Manag. 2016;36:104252. https://doi.org/10.1016/j.ijinfomgt.2016.06.009.

81. Markopoulos P, Romero N, van Baren J, et al. Keeping in touch with the family: home and away with the ASTRA Awareness System. In: Proceedings of the CHI '04 Extended Abstracts on Human Factors in Computing Systems (CHI EA '04). Wien; 2004. pp 1351-1354

82. Marshall J. Creating illusion in computer aided performance. Dissertation, University of Nottingham. 2009

83. Maruping LM, Magni M. Motivating employees to explore collaboration technology in team contexts. MIS Q. 2015;39:1-16.

84. Mateescu M, Kropp M, Burkhard R, et al. aWall: a socio-cognitive tool for agile team collaboration using large multi-touch wall systems. In: Proceedings of the 2015 international conference on interactive tabletops and surfaces (ITS '15). Madeira; 2015. pp 361-366

85. Mom TJM, van den Bosch FAJ, Volberda HW. Understanding variation in managers' ambidexterity: investigating direct and interaction effects of formal structural and personal coordination mechanisms. Organ Sci. 2009;20:812-28. https://doi.org/ 10.1287/orsc. 1090.0427.

86. Nabusiu BJ. Benefits that a business can derive from humancomputer interaction interventions. Pretoria: Masterarbeit, University of South Africa; 2014.

87. Oguz A, Singh R (2017) The effectiveness of enterprise social media use: impact of national culture and organizational culture. In: Proceedings of 23rd America's Conference on Information Systems: A Tradition of Innovation (AMCIS '17). Boston, pp $1-5$

88. Ollagnier-Beldame M. The use of digital traces: a promising basis for the design of adapted information systems? Int J Comput Sci Inf Syst. 2011;6:24-45.

89. Ott F. CommunityMirrors: interaktive Großbildschirme als ubiquitäre natural user interfaces für kooperationssysteme. Schriften zur Soziotechnischen Integr 5. 2018. https://doi.org/10.18726/ 2018.

90. Ott F, Richter A, Koch M. Einsatz großer wandbildschirme als fenster in kooperationssysteme. In: Proceedings of mensch und computer 2009 (MuC '09). Berlin; 2009. pp 1-10

91. Parra G, Klerkx J, Duval E. Understanding engagement with interactive public displays: an awareness campaign in the wild. In: Proceedings of the international symposium on pervasive displays (PerDis '14). New York; 2014. pp 180-185

92. Phillips KW, Northcraft GB, Neale MA. Surface-level diversity and decision-making in groups: when does deep-level similarity help? Group Process Integr Relat. 2006;9:467-82. https://doi. org/10.1177/1368430206067557.

93. Pifarré M, Cobos R, Argelagós E. Incidence of group awareness information on students' collaborative learning processes. J Comput Assist Learn. 2014;30:300-17. https://doi.org/10.1111/ jcal.12043.

94. Postmes T, Spears R, Lea M. Breaching or building social boundaries? Commun Res. 1998;25:689-715. https://doi.org/10.1177/ 009365098025006006.

95. Qi C, Chau PYK. Will enterprise social networking systems promote knowledge management and organizational learning? An empirical study. J Organ Comput Electron Commer. 2018;28:31-57. 
96. Raeth P, Kügler M, Smolnik S. The impact of organizational social web site usage on work performance: a multilevel structural interaction perspective. In: Proceedings of the 45th annual hawaii international conference on system sciences (HICSS '12). Maui; 2012. pp 4011-4020

97. Raeth P, Smolnik S. Antecedents and consequences of corporate weblog usage in the intranet: a process perspective. In: Proceedings of the 2010 43rd Hawaii international conference on system sciences (HICSS '10). Koloa; 2010. pp 1-10

98. Rettie R. Connectedness, awareness and social presence. In: Proceedings of the 6th annual international workshop on presence (PRESENCE '03). Aalborg; 2003. pp 474-484

99. Richter A, Koch M. Social software: status quo und zukunft. In: Technischer bericht. Neubiberg: Universität der Bundeswehr München; 2007. p. 1-49.

100. Rubegni E, Memarovic N, Langheinrich M. Talking to strangers: using large public displays to facilitate social interaction. Lect Notes Comput Sci. 2011;6770:195-204. https://doi.org/10.1007/ 978-3-642-21708-1_23.

101. Schreurs B, de Laat M. The network awareness tool: a web 2.0 tool to visualize informal networked learning in organizations. Comput Hum Behav. 2014;37:385-94. https://doi.org/10.1016/j. chb.2014.04.034

102. Schryen G, Bodenstein C. A decision-theoretic foundation of IS Business Value Research. In: Proceedings of the 18th European conference on information systems (ECIS '10). Pretoria; 2010. pp 1-12

103. Schubert P, Williams SP. Management der nutzenrealisierung aus informationstechnologie. In: Proceedings of the 11th international conference on wirtschaftsinformatik (WI '13). Leipzig; 2013. pp 593-607

104. Seebach C, Beck R, Pahlke I. Situation awareness through social collaboration platforms in distributed work environments. In: Proceedings of the thirty second international conference on information systems (ICIS '11). Shanghai; 2011. pp 1-22

105. Sendín M, López-Gil J-M, López-Jaquero V. Validation of a framework for enriching human-computer-human interaction with awareness in a SeamlessWay. Interact Comput. 2014;26:433-49. https://doi.org/10.1093/iwc/iwt046.

106. Sherman DK, Cohen GL, Nelson LD, et al. Affirmed yet unaware: exploring the role of awareness in the process of self-affirmation. J Pers Soc Psychol. 2009;97:745-64. https://doi.org/10. 1037/a0015451.

107. Sniehotta FF, Nagy G, Scholz U, Schwarzer R. The role of action control in implementing intentions during the first weeks of behaviour change. Br J Soc Psychol. 2006;45:87-106. https:// doi.org/10.1348/014466605X62460.

108. Springer. Springer Link: providing researchers with access to millions of scientific documents. 2021. https://link.springer.com

109. Stumpp P. Strategisches KPI-reporting und nutzenmodell für die unternehmensweite informationsbereitstellung. Inf Wiss Prax. 2012;63:183-8. https://doi.org/10.1515/iwp-2012-0023.

110. Tausch S, Hausen D, Kosan I et al. Groupgarden: supporting brainstorming through a metaphorical group mirror on table or wall. In: Proceedings of the nordic conference on human-computer interaction (NordiCHI '14). Helsinki; 2014. pp 541-550

111. Teigland R, Wasko MM. Integrating knowledge through information trading: examining the relationship between boundary spanning communication and individual performance. Decis Sci. 2003;34:261-86.

112. Thompson LF, Coovert MD. Teamwork online: the effects of computer conferencing on perceived confusion, satisfaction, and postdiscussion accuracy. Group Dyn Theory Res Pract. 2003;7:135-51. https://doi.org/10.1037/1089-2699.7.2.135.

113. Tomitsch M, Ackad CJ, Dawson O et al. Who cares about the content? an analysis of playful behaviour at a public display. In: Proceedings of the international symposium on pervasive displays (PerDis '14). Kopenhagen; 2014. pp 160-165

114. Valkanova N, Walter R, Moere A, Müller J. MyPosition: sparking civic discourse by a public interactive poll visualization. In: Proceedings of the 17th ACM conference on computer supported cooperative work and social computing (CSCW '14). Baltimore; 2014. pp 1323-1332

115. Vermeulen J, Luyten K, Coninx K et al. Proxemic flow: dynamic peripheral floor visualizations for revealing and mediating large surface interactions. In: Adjunct proceedings of the 15th international conference on human-computer interaction (INTERACT '15). Bamberg; 2015. pp 264-281

116. Vyas DM. Designing for awareness: an experience-focused HCI perspective. Dissertation, University of Twente. 2011

117. Wagner S, Deissenboeck F. Defining productivity in software engineering. In: Rethinking productivity in software engineering. New York: Springer; 2019. p. 29-38.

118. Wiesche M, Jurisch M, Yetton P, Krcmar H. Grounded theory methodology in information systems research. MIS Q. 2017;41:685-701.

119. Williamson JR, Sundén D, Bradley J. GlobalFestival: evaluating real world interaction on a spherical display julie. In: Proceedings of the 2015 ACM international joint conference on pervasive and ubiquitous computing (UbiComp '15). Osaka; 2015. pp 1251-1261

120. Wilson S. Presence in social networks. In: Hatzipanagos S, Warburton S, editors. Handbook of research on social software and developing community ontologies. New York: Hershey; 2009. p. 493-511.

121. Zhang Y, Müller J, Chong MK et al. GazeHorizon: enabling passers-by to interact with public displays by gaze. In: International conference on ubiquitous computing (UbiComp '14). Seattle; 2014. pp 559-563

Publisher's Note Springer Nature remains neutral with regard to jurisdictional claims in published maps and institutional affiliations. 